\title{
Article \\ Globotrioasylsphingosine Levels and Optical Coherence Tomography Angiography in Fabry Disease Patients
}

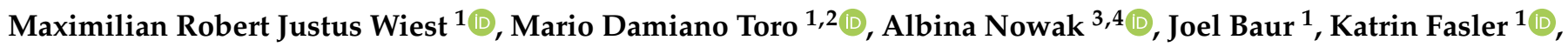 \\ Timothy Hamann ${ }^{1}$, Mayss Al-Sheikh ${ }^{1}$ and Sandrine Anne Zweifel ${ }^{1, *}$ \\ 1 Department of Ophthalmology, University Hospital Zurich, University of Zurich, 8091 Zurich, Switzerland; \\ maximilian.wiest@usz.ch (M.R.J.W.); toro.mario@email.it (M.D.T.); mail@joelbaur.ch (J.B.); \\ katrin.fasler@usz.ch (K.F.); timothy.hamann@usz.ch (T.H.); mayss.al-sheikh@usz.ch (M.A.-S.) \\ 2 Faculty of Medical Sciences, Collegium Medicum, Cardinal Stefan Wyszyński University, \\ 01815 Warsaw, Poland \\ 3 Department of Endocrinology and Clinical Nutrition, University Hospital Zurich, University of Zurich, \\ 8091 Zurich, Switzerland; albina.nowak@usz.ch \\ 4 Department of Internal Medicine, Psychiatry University Clinic Zurich, 8091 Zurich, Switzerland \\ * Correspondence: sandrine.zweifel@usz.ch; Tel.: +41-44-255-87-94
}

Citation: Wiest, M.R.J.; Toro, M.D.; Nowak, A.; Baur, J.; Fasler, K.;

Hamann, T.; Al-Sheikh, M.; Zweifel, S.A. Globotrioasylsphingosine Levels and Optical Coherence Tomography Angiography in Fabry Disease Patients. J. Clin. Med. 2021, 10, 1093. https://doi.org/10.3390/jcm10051093

Academic Editor: Gianluca Manni

Received: 27 January 2021

Accepted: 4 March 2021

Published: 5 March 2021

Publisher's Note: MDPI stays neutral with regard to jurisdictional claims in published maps and institutional affiliations.

Copyright: (c) 2021 by the authors. Licensee MDPI, Basel, Switzerland. This article is an open access article distributed under the terms and conditions of the Creative Commons Attribution (CC BY) license (https:// creativecommons.org/licenses/by/ $4.0 /)$.

\begin{abstract}
Background: To date, there are no studies associating the dried blood spot (DBS) levels of globotrioasylsphingosine (lysoGb3) with quantitative optical coherence tomography angiography (OCTA) parameters in Fabry disease (FD) patients. Here, we aimed to investigate the association between OCTA vessel density (VD), vessel length density (VLD) with DBS lysoGb3. Methods: A retrospective, single center analysis of all consecutive FD patients enrolled the Department of Ophthalmology of the University Hospital of Zurich from 1 December 2017 to 9 September 2020. An association between VD and VLD detected by OCTA and lysoGb3 was investigated using a linear mixed model. Results: A total of 57 FD patients (23 male, 34 female; 109 eyes) were included. Fortyone patients suffered from the classic phenotype and 16 from the later-onset phenotype. LysoGb3 inversely correlated with VD and VLD in both the superficial (VD: $p=0.034$; VLD: $p=0.02$ ) and deep capillary plexus (VD: $p=0.017$; VLD: $p=0.018$ ) in the overall FD cohort. Conclusions: Our study shows an association between lysoGb3 and OCTA VD and VLD. This supports the hypothesis that quantitative OCTA parameters might be useful as diagnostic biomarkers for evaluating systemic involvement in FD, and possibly other diseases.
\end{abstract}

Keywords: fabry disease; globotrioasylsphingosine; optical coherence tomography angiography; lysosomal storage disorder; vessel density; vessel length density

\section{Introduction}

Fabry disease (FD) is a rare lysosomal storage disorder in which globotrioasylsphingosine (Gb3) accumulates in fluids and lysosomes of patients [1]. Mutations in the $\alpha$ galactosidase gene (GLA) cause a decrease in overall activity of the enzyme $\alpha$-galactosidase $(\alpha-\mathrm{Gal} A)[2]$, which leads to accumulation of the aforementioned substrate in tissues and organs including the heart, kidney, the nervous system, the skin, vascular endothelium and the eye and causes progressive organ dysfunction ${ }^{3}$. Renal failure, cardiovascular disease and premature strokes are amongst the most common and severe fatal complications [1-5].

As an X-linked disease, FD predominantly affects males, the incidence being 1 in 40,000 to 117,000 live births for males [6,7]. Two phenotypes exist: the classic male phenotype with very low $\alpha-$ Gal A activity can be distinguished from the later-onset male phenotype with significant residual $\alpha$-Gal A activity by manifestation of early symptoms such as acroparesthesias, abdominal cramping and hypohydrosis, while the later-onset patients typically develop hypertrophic cardiomyopathy or chronic kidney disease during adulthood $[2,8,9]$. In heterozygous females, due to random X-chromosomal inactivation, 
the phenotypes are more heterogenous, with a disease activity ranging from very mild to rather severe [10].

Ocular manifestations usually occur in the classic phenotype sometimes contributing to an early diagnosis of the disease [11]. The most common, and often key in early diagnosis of FD, is a vortex-like opacity found in the cornea, cornea verticillata (CV) [12-14]. Another specific finding, in fact, the only pathognomonic ocular finding, is a spoke-like posterior cataract which can be observed in $9.8 \%$ of females and $21.9 \%$ of males $[15,16]$. FD also manifests in the retina. Previous studies report an increased tortuosity of retinal vessels in patients suffering predominantly from the classic phenotype [9].

In the last decades, intravenous enzyme replacement therapy (ERT) with agalsidase alfa (Replagal ${ }^{\circledR}$, Shire, Lexington, MA, USA) or agalsidase beta (Fabrazyme ${ }^{\circledR}$, Sanofi Genzyme, Cambridge, MA, USA) has become the gold standard therapy of FD [17-19]. Recently, pharmacological chaperone therapy has been approved for amenable mutations [20].Under ERT, LysoGb3 levels have been reported to decrease, objective clinical parameters such as cerebral blood flow and symptoms to improve $[21,22]$. Better results have been reported when ERT was initiated before fibrosis and permanent organ damage has occurred [21].

Optical coherence tomography angiography (OCTA) is a non-invasive infrared-based imaging technique that has been developed in recent years [23]. It is capable of delivering structural and angiographic analysis without invasive measures such as intravenous dye injection [24]. OCTA is able to provide quantitative microvascular information such as vessel density (VD) and vessel length density (VLD) $[25,26]$. Additionally, OCTA allows a clear and detailed visualization of retinal and choroidal microvasculature, and it is useful either for diagnostic purposes or for guiding treatment, and monitoring different retinal diseases [27]. Past publications have shown that differences in quantitative OCTA parameters, such as VD and VLD in between patients suffering from FD and healthy controls are detectable [28-30]. Furthermore, a recent publication from Cennamo et al. [31] from December 2020 has demonstrated that quantitative OCTA parameters inversely correlate with echocardiographic parameters of myocardial disease and, thus, might be used as surrogate biomarkers for systemic involvement and progression in and of FD. Indeed, OCTA, identifying subclinical microvascular modifications [24], could potentially be used as a "multidisciplinary" instrument, not exclusively by ophthalmologists, for the early diagnosis and management of several systemic diseases [32].

To our knowledge to date, there are no studies associating the dried blood spot (DBS) levels of globotrioasylceramide (lysoGb3) with quantitative OCTA parameters. In this study, we aimed to investigate the association between OCTA VD, VLD of the superficial (SCP) and deep retinal capillary plexus (DCP) with DBS lysoGb3.

\section{Materials and Methods}

This is a single-center, retrospective analysis of a cohort of consecutive patients with genetically proven diagnosis of FD who underwent annual ophthalmological checkup at the medical retina unit of the Department of Ophthalmology, University Hospital of Zurich, Switzerland from 1 December 2017 to 9 September 2020. The institutional review board approved this study (Cantonal Ethics Committee, Canton of Zurich, BASEC-No. 201902043) and the tenets of the Declaration of Helsinki were followed. A written informed consent for the processing of personal data was obtained from each patient.

Inclusion criteria were as follows: genetically confirmed diagnosis of FD, minimal age of 16 years of age. Exclusion criteria were: evidence of ocular and systemic diseases unrelated to FD, current or previous macular and retinal vascular diseases, diagnosis of glaucoma, congenital eye disease, high myopia ( $>4$ dioptres), significant lens opacification and reduced-quality OCTA images (signal strength of $7 / 10$ or lower).

All patients underwent a blood test and an ophthalmological examination with best corrected visual acuity (BCVA), intraocular pressure (IOP) measurement, slit lamp examination of the anterior segment and biomicroscopy of the fundus, ultrawide-field scanning 
laser ophthalmoscopy (Optomap, Optos, Marlborough, MA, USA), spectral-domain optical coherence tomography (SD-OCT) and swept-source OCTA.

LysoGb3 concentrations were measured in DBS using highly sensitive electrospray ionization liquid chromatography tandem mass spectrometry (ESI LC-MS/MS), modified according to Gold et al. [33] as previously described by Nowak et al. [34]. A 7-point serum calibrator and an internal standard for LysoGb3 quantification (covering the analytic range from 0 to $120 \mathrm{ng} / \mathrm{mL}$; lower limit of quantification: $0.2 \mathrm{ng} / \mathrm{mL}$ ), and three calibrator levels $(3,30$ and $100 \mathrm{ng} / \mathrm{mL}$ ) for quality control were used (ARCHIMED Life Science $\mathrm{GmbH}$, Vienna, Austria; www.archimedlife.com accessed on 1 March 2021).

BCVA was assessed using glasses with refractory values obtained using an autorefractometer (NT-530/510 ${ }^{\circledR}$, NIDEK Inc., San Jose, CA, USA) values were then converted to Early Treatment Diabetic Retinopathy Study (ETDRS) number values [35]. Intraocular pressure measurements were acquired using the same device.

OCTA was performed using the swept-source PLEX Elite 9000 device, software version 2.0.1.47652 (Carl Zeiss Meditec Inc., Dublin, CA, USA). $3 \mathrm{~mm} \times 3 \mathrm{~mm}$ scans centered on the fovea were acquired by a well-trained, certified ophthalmologist. Scans with a signal strength of 8 out of 10 or higher were included, as signal strength has been shown to influence quantitative measurements in OCTA [36]. Additionally, scans with incorrect centration, bad focus, motion or errors in projection artifact removal were excluded.

Quantitative parameters of the $3 \times 3 \mathrm{~mm}$ cube scans were automatically generated using layer segmentation produced by the instrument software and prototype analysis vascular density quantification software (Macular Density v.0.7.1, ARI Network Hub, Carl Zeiss Meditec Inc., Dublin, CA, USA) supplied by the manufacturer. Output values are vascular density metrics previously used in the literature, such as VD, which represents the fraction of a measured region with perfusion signal and VLD, which represents the total length of perfused vasculature in a measured area, given in millimeters of perfused vasculature per square millimeter of area, or inverse millimeters $\left(\mathrm{mm}^{-1}\right)[37,38]$. The analyzed region of interest was the innermost ring of the ETDRS grid (inner ring, iR), with an inner diameter of $1 \mathrm{~mm}$ and an outer diameter of $3 \mathrm{~mm}$, centered on the fovea [35].

Data such as age at examination date, gender, FD phenotype, BCVA, IOP, as well as the presence or absence of FD associated ophthalmological findings, as well as the lysoGb3 concentration from DBS samples and systemic involvement were acquired from electronic health reports and used for statistical analysis.

\section{Statistical Analysis}

Statistical analysis was performed using SPSS software (version 26, IBM Corporation, Armonk, NY, USA). Clinical parameters and OCTA data were displayed using descriptive statistics. To test whether lysoGb3 had an influence on OCTA parameters, a linear mixed model was used. This allows for inclusion of both eyes from patients, wherever both were available by correcting for multiple measurements (right eye, left eye, repeated covariance setting: compound symmetry).

Analysis of the influence of lysoGb3 on OCTA parameters in the overall cohort was performed. The influence of laterality, sex and age were accounted for by including laterality and sex as cofactors and age as covariance. In case of a $p$-value of lower than 0.05 for the type III test of fixed effect (F-test), the estimates of fixed effect of lysoGb3 on the OCTA parameter were reviewed in detail. The aforementioned analysis was performed for VD in the SCP, VD in the DCP, VLD in the SCP and VLD in the DCP, for parameters gathered from the ETDRS grid inner ring area.

The statistical analysis was repeated for the following subgroups: male patients, female patients, classic phenotype patients and later-onset patients. Data for the overall cohort and the male and female subgroups were plotted as scatterplots with fit lines. For easier viewability, lysoGb3 values underwent natural log transformation (Ln.lysoGb3). 


\section{Results}

Out of the 63 patients identified, 6 had to be excluded because no OCTA imaging of sufficient quality was available. Of the remaining 57 patients with 114 eyes, 5 eyes had to be excluded because of incorrect centering or bad focus ( 3 and 2, respectively). Among 109 eyes, one DCP segmentation had to be excluded due to segmentation failure.

A total of 57 (34 female, 23 male) genetically proven FD patients with 109 (57 right, 52 left) eyes and 109 SCP and 108 DCP segmentations were included for analysis. Forty-one patients suffered from the classic phenotype ( $27 \mathrm{female}, 14 \mathrm{male}$ ) and 16 from the later-onset phenotype ( 7 female, 9 male). Of all the patients, 40 ( 22 male, 18 female, $70.2 \%$ overall) were under ERT. Mean age was $43.4( \pm 15.3)$ years and mean lysoGb3 concentration was 16.7( \pm 21.03 ; min. $1.5 ;$ max. 86.7) $\mathrm{ng} / \mathrm{mL}$.

Cornea verticillata was observed in $74(67.9 \%)$ and retinal vessel tortuosity in 52 (47.7\%) eyes. None displayed a spoke-like posterior cataract. Mean BCVA was 1.04 $( \pm 0.23)$ and mean IOP $14.8( \pm 2.9) \mathrm{mmHg}$. A summary of demographics, genetical and clinical characteristics are shown in Tables 1-3.

Table 1. Demographics and clinical characteristics of Fabry disease (FD) patients.

\begin{tabular}{|c|c|c|c|c|c|}
\hline & & & & \multicolumn{2}{|c|}{ FD Patients $n=57$} \\
\hline \multirow{2}{*}{ gender } & & male & & \multicolumn{2}{|c|}{23} \\
\hline & & female & & \multicolumn{2}{|c|}{34} \\
\hline \multicolumn{4}{|c|}{ mean age (years) $\pm S D$} & \multicolumn{2}{|c|}{$43.4 \pm 15.3$} \\
\hline \multirow{2}{*}{ FD phenotype } & \multicolumn{3}{|c|}{ classic } & \multicolumn{2}{|c|}{41} \\
\hline & \multicolumn{3}{|c|}{ later-onset } & \multicolumn{2}{|r|}{16} \\
\hline \multirow{3}{*}{ mean lysoGb3 $(\mathrm{ng} / \mathrm{mL}) \pm \mathrm{SD}$} & \multicolumn{3}{|c|}{ overall } & \multicolumn{2}{|c|}{$16.7 \pm 21.03$} \\
\hline & \multicolumn{3}{|c|}{ male } & \multicolumn{2}{|c|}{$31.8 \pm 27.03$} \\
\hline & \multicolumn{3}{|c|}{ female } & \multicolumn{2}{|c|}{$6.9 \pm 3.52$} \\
\hline \multirow{2}{*}{ enzyme replacement therapy * } & \multicolumn{3}{|c|}{ yes } & \multicolumn{2}{|c|}{40} \\
\hline & \multicolumn{3}{|c|}{ no } & \multicolumn{2}{|r|}{17} \\
\hline \multirow{2}{*}{\multicolumn{6}{|c|}{$\begin{array}{l}\text { n: number; lysoGb3: Globotriaosylceramide in dried blood spot samples; ng: nanograms; ml: milliliter } \\
\text { * agalsidase beta or ANN-agalsidase alfa. } \\
\text { Table 2. } \alpha \text {-galactosidase gene (GLA) mutations observed in the pooled Fabry disease group an } \\
\text { respective subgroups. }\end{array}$}} \\
\hline & & & & & \\
\hline \multirow[t]{2}{*}{ Mutation } & \multicolumn{5}{|c|}{ Frequency } \\
\hline & led FD & Male * & Female * & Classic* & Later-Onset * \\
\hline c. $1033 \mathrm{~T}>\mathrm{C}$ & 6 & 1 & 5 & 6 & 0 \\
\hline c.1055-1057dupCTA & 2 & 1 & 1 & 2 & 0 \\
\hline c.114delCTT & 1 & 0 & 1 & 1 & 0 \\
\hline c.1167dupT & 2 & 0 & 2 & 2 & 0 \\
\hline c.1168insT & 2 & 0 & 2 & 2 & 0 \\
\hline c.1196G > C & 1 & 1 & 0 & 0 & 1 \\
\hline c. $125 \mathrm{~T}>\mathrm{C}$ & 3 & 1 & 2 & 3 & 0 \\
\hline c. $337 \mathrm{~T}>\mathrm{C}$ & 8 & 3 & 5 & 1 & 7 \\
\hline c. $370-2 \mathrm{~A}>\mathrm{G}$ & 1 & 1 & 0 & 1 & 0 \\
\hline c. $514 \mathrm{~T}>\mathrm{C}$ & 1 & 0 & 1 & 1 & 0 \\
\hline c. $518 \mathrm{C}>\mathrm{T}$ & 1 & 1 & 0 & 1 & 0 \\
\hline
\end{tabular}


Table 2. Cont.

\begin{tabular}{|c|c|c|c|c|c|}
\hline \multirow[t]{2}{*}{ Mutation } & \multicolumn{5}{|c|}{ Frequency } \\
\hline & Pooled FD & Male * & Female * & Classic* & Later-Onset* \\
\hline c.559-560delAT & 1 & 1 & 0 & 1 & 0 \\
\hline c. $581 C>\mathrm{T}$ & 7 & 2 & 5 & 7 & 0 \\
\hline c. $613 \mathrm{C}>\mathrm{T}$ & 1 & 1 & 0 & 0 & 1 \\
\hline c. $640-3 C>G$ & 1 & 0 & 1 & 1 & 0 \\
\hline c. $644 \mathrm{~A}>\mathrm{G}$ & 1 & 1 & 0 & 0 & 1 \\
\hline c. $680 \mathrm{G}>\mathrm{A}$ & 1 & 0 & 1 & 1 & 0 \\
\hline c. $704 \mathrm{C}>\mathrm{G}$ & 2 & 0 & 2 & 2 & 0 \\
\hline c.743-744delTA & 2 & 1 & 1 & 2 & 0 \\
\hline c.744-745delTA & 3 & 2 & 1 & 3 & 0 \\
\hline c.796G > T & 1 & 1 & 0 & 1 & 0 \\
\hline c. $827 \mathrm{G}>\mathrm{A}$ & 1 & 1 & 0 & 1 & 0 \\
\hline c. $870 \mathrm{G}>\mathrm{C}$ & 1 & 0 & 1 & 0 & 1 \\
\hline c. $899 \mathrm{~T}>\mathrm{A}$ & 1 & 1 & 0 & 1 & 0 \\
\hline c. $901 \mathrm{C}>\mathrm{T}$ & 1 & 2 & 1 & 1 & 0 \\
\hline c. $902 \mathrm{G}>\mathrm{A}$ & 5 & 3 & 2 & 0 & 5 \\
\hline
\end{tabular}

${ }^{*}$ referring to male, female, classic phenotype and later-onset phenotype subgroups.

Table 3. Ocular characteristics of study cohort.

\begin{tabular}{ccc}
\hline \multirow{2}{*}{ laterality } & \multicolumn{2}{c}{ Eyes $n=109$} \\
\hline \multirow{2}{*}{ cornea verticillata } & right & 57 \\
\cline { 2 - 3 } & left & 52 \\
\cline { 2 - 3 } retinal vessel tortuosity & yes & 74 \\
\cline { 2 - 3 } & no & 35 \\
\hline mean BCVA(EDTRS letters) & yes & 52 \\
\hline \multicolumn{2}{c}{ mean IOP(mmHg) } & $85.32 \pm 4.92$ \\
\hline
\end{tabular}

n: number; BCVA: best corrected visual acuity; ETDRS: Early Diabetic Treatment Retinopathy Study; IOP: intraocular pressure.

Mean VD of the SCP was $0.382 \pm 0.023$ for the inner ring area. For the DCP, mean VD was $0.275 \pm 0.049$. The mean VLD of the SCP was $17.183 \mathrm{~mm}^{-1} \pm 1.262 \mathrm{~mm}^{-1}$. In the DCP, VLD measured was lower with $12.747 \mathrm{~mm}^{-1} \pm 2.248 \mathrm{~mm}^{-1}$ for the inner ring area.

Detailed information about means and standard deviations (SD) of OCTA parameters are shown in Table 4.

In the pooled FD group, lysoGb3 was identified as a statistically significant $(p<0.05)$ influence on VD and VLD in both, the SCP and DCP segmentations. The estimates of regression were $-0.000338(p=0.034)$ for $\mathrm{VD}$ in $\mathrm{SCP},-0.000714(p=0.020)$ for $\mathrm{VD}$ in $\mathrm{DCP}$, $-0.020157(p=0.17)$ for VLD in SCP and $-0.032385(p=0.018)$ for VLD in DCP. 
Table 4. Mean values of OCTA parameters.

\begin{tabular}{|c|c|c|c|}
\hline \multicolumn{2}{|c|}{ OCTA Parameter } & Mean & $\pm \mathbf{S D}$ \\
\hline \multicolumn{4}{|c|}{ pooled FD group } \\
\hline \multirow{2}{*}{ SCP } & VD & 0.382 & 0.023 \\
\hline & VLD & 17.183 & 1.261 \\
\hline \multirow{2}{*}{ DCP } & VD & 0.275 & 0.049 \\
\hline & VLD & 12.747 & 2.248 \\
\hline \multicolumn{4}{|c|}{ male FD subgroup } \\
\hline \multirow{2}{*}{ SCP } & VD & 0.379 & 0.020 \\
\hline & VLD & 16.955 & 1.113 \\
\hline \multirow{2}{*}{ DCP } & VD & 0.262 & 0.049 \\
\hline & VLD & 12.137 & 2.207 \\
\hline \multicolumn{4}{|c|}{ female FD subgroup } \\
\hline \multirow{2}{*}{ SCP } & VD & 0.384 & 0.026 \\
\hline & VLD & 17.338 & 1.340 \\
\hline \multirow{2}{*}{ DCP } & VD & 0.283 & 0.047 \\
\hline & VLD & 13.167 & 2.196 \\
\hline \multicolumn{4}{|c|}{ classic phenotype FD subgroup } \\
\hline \multirow{2}{*}{ SCP } & VD & 0.379 & 0.025 \\
\hline & VLD & 16.983 & 1.276 \\
\hline \multirow{2}{*}{ DCP } & VD & 0.269 & 0.051 \\
\hline & VLD & 12.486 & 2.320 \\
\hline \multicolumn{4}{|c|}{ later-onset phenotype FD subgroup } \\
\hline \multirow{2}{*}{ SCP } & VD & 0.391 & 0.017 \\
\hline & VLD & 17.712 & 1.073 \\
\hline \multirow{2}{*}{ DCP } & VD & 0.289 & 0.043 \\
\hline & VLD & 13.427 & 1.922 \\
\hline
\end{tabular}

OCTA: Optical coherence tomography angiography; SD: standard deviation; FD: Fabry Disease; SCP: superficial capillary plexus; VD: vessel density; VLD: vessel length density; DCP: deep capillary plexus.

When repeating this analysis for the subgroup of male FD patients, we found that lysoGb3 showed a statistically significant influence for the VD and VLD in the SCP only with estimates of regression of $-0.000349(p=0.014)$ for VD and $-0.021716(p=0.005)$ for VLD. LysoGb3 did not appear as a statistically significant effect on VD and VLD in the DCP of the male subgroup. In the female subgroup as well as the subgroups of classic and later-onset phenotypes, no statistically significant influences of lysoGb3 were detected. A detailed view of $p$-values and estimates of regression with standard error (SE) are shown in Table 5 and a visualization of data for the pooled FD patients in Figure 1. 


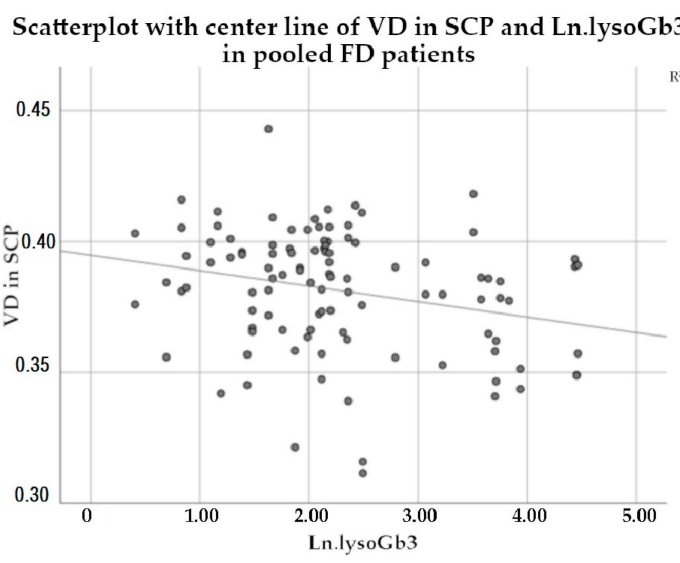

Scatterplot with center line of VD in DCP and Ln.lysoGb3

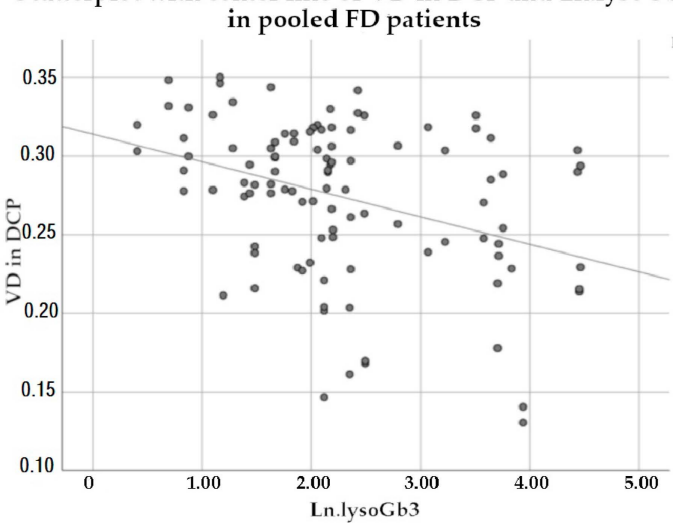

Scatterplot with center line of VLD in SCP and Ln.lysoGb3

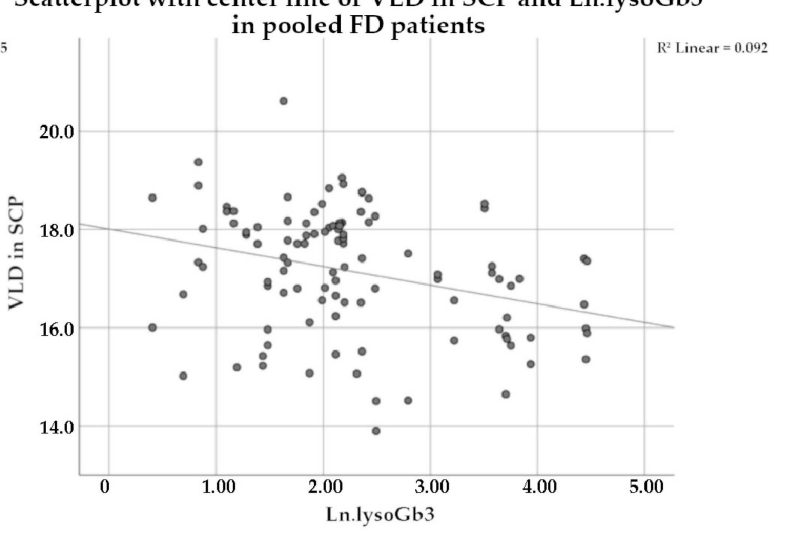

Scatterplot with center line of VLD in DCP and Ln.lysoGb3

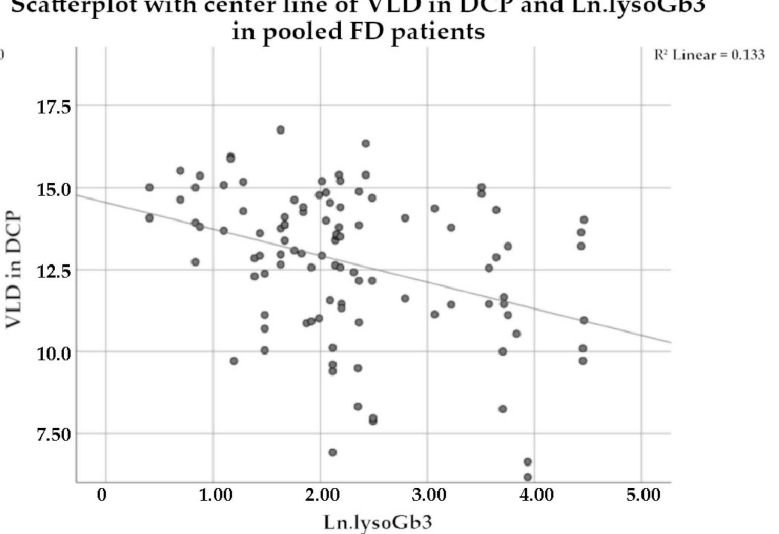

Figure 1. Scatterplots with centerline of VD and VLD in SCP and DCP of FD patients. In the upper left plot, the inverse association of VD in SCP with the logarithmized values of lysoGb3 (Ln.lysoGb3) is shown. The other plots show the inverse association for VLD in SCP (top right), VD in DCP (bottom left), and VLD in DCP (bottom right) with Ln.lysoGb3. Abbreviations: VD: vessel density; VLD: vessel length density; SCP: superficial capillary plexus; DCP: deep capillary plexus; FD: Fabry Disease; Ln.LysoGb3: logarithmized lysoGb3.

Table 5. Association of lysoGb3 and OCTA parameters.

\begin{tabular}{|c|c|c|c|c|}
\hline \multicolumn{2}{|c|}{ OCTA Parameter } & Regression Estimator & SE & $p$-Value * \\
\hline \multicolumn{5}{|c|}{ pooled FD group } \\
\hline \multirow{2}{*}{ SCP } & VD & -0.000338 & 0.000155 & 0.034 \\
\hline & VLD & -0.020157 & 0.008128 & 0.017 \\
\hline \multirow{2}{*}{ DCP } & VD & -0.000714 & 0.000297 & 0.020 \\
\hline & VLD & -0.032385 & 0.013286 & 0.018 \\
\hline \multicolumn{5}{|c|}{ male FD subgroup } \\
\hline \multirow{2}{*}{ SCP } & VD & -0.000349 & 0.000129 & 0.014 \\
\hline & VLD & -0.021716 & 0.006728 & 0.005 \\
\hline \multirow{2}{*}{ DCP } & VD & -0.000655 & 0.000359 & 0.084 \\
\hline & VLD & -0.030220 & 0.015725 & 0.070 \\
\hline \multicolumn{5}{|c|}{ female FD subgroup } \\
\hline \multirow{2}{*}{ SCP } & VD & -0.000287 & 0.001157 & 0.806 \\
\hline & VLD & -0.018082 & 0.060351 & 0.766 \\
\hline
\end{tabular}


Table 5. Cont.

\begin{tabular}{ccccc}
\hline \multirow{2}{*}{ OCTA Parameter } & Regression Estimator & SE & $p$-Value * \\
\hline \multirow{2}{*}{ DCP } & VD & -0.001237 & 0.001745 & 0.484 \\
\cline { 2 - 5 } & VLD & -0.053284 & 0.080509 & 0.513 \\
\hline \multirow{2}{*}{ SCP } & VD & classic phenotype FD subgroup & \\
\cline { 2 - 5 } & VLD & -0.000142 & 0.000234 & 0.547 \\
\hline \multirow{2}{*}{ DCP } & VD & -0.009219 & 0.011554 & 0.430 \\
\cline { 2 - 5 } & VLD & -0.000333 & 0.000413 & 0.426 \\
\hline \multirow{2}{*}{ SCP } & later-onset phenotype FD subgroup & 0.018550 & 0.432 \\
\cline { 2 - 5 } & VD & -0.001530 & 0.002049 & 0.471 \\
\hline \multirow{2}{*}{ DCP } & VD & -0.051812 & 0.143124 & 0.725 \\
\cline { 2 - 5 } & VLD & -0.004082 & 0.005504 & 0.474 \\
\hline$O$
\end{tabular}

OCTA: Optical coherence tomography angiography; SE: standard error; FD: Fabry's Disease; SCP: superficial capillary plexus; VD: vessel density; VLD: vessel length density; DCP: deep capillary plexus; * Type III test for fixed effect; $p$ was significant if $p<0.05$.

\section{Discussion}

In this study, we observed an inverse association between VD and VLD with lysoGb3 DBS levels in our cohort of genetically proven FD patients. We also show an inverse association of lysoGb3 with VD and VLD of the SCP of our male subgroup, but not in the DCP. However, in the other subgroups, we were unable to detect any statistically significant association.

The clinical presentation of FD can vary substantially, depending on the residual activity of $\alpha$-galactosidase [2]. Clinical findings range from the initially mild, often nonsystem involving later-onset phenotype to the severe, classic phenotype with almost no remaining enzyme activity [2]. Different authors have reported associations of lysoGb3 levels to cardiac, renal [39], pulmonary changes [40], as well as neurological deficits [41,42]. Aerts et al. have postulated that elevated lysoGb3 concentrations play a key role in the pathogenesis of FD and lysoGb3 may be considered as the hallmark of FD [43]. It has been shown that inflammation and innate immune response in FD are caused by elevated lysoGb3. Increased exposure of dendritic Toll-like receptors to lysoGb3 can trigger overexpression of inflammatory molecules and tissue inflammation, which leads to fibrosis and ultimately organ dysfunction and/or failure [44-50]. LysoGb3 levels in DBS samples are highly correlated with plasma lysoGb3 [34] and are used as a diagnostic and predictive biomarker in the treatment of FD patients [40,51]. Indeed, Nowak et al. have demonstrated that lysoGb3 is a useful biomarker for the diagnosis of FD in heterozygotes and can assist in determining whether heterozygotes should be considered for treatment, despite normal $\alpha$-GalA activity [52].

Previous studies have shown that OCT-A is able to detect microvascular retinal alterations and could be useful as a biomarker in the early diagnosis and follow-up of patients affected by different systemic diseases $[32,37,53,54]$. However, despite the progress in the diagnosis and the treatment of FD, evidence of correlations of OCTA parameters and systemic findings is low and there are only few studies highlighting such associations $[31,55]$. Cennamo et al. have shown that the VD of both the SCP and DCP inversely associate with different echocardiographic parameters (E/e' ratio, systolic pulmonary arterial pressure, left atrial volume index and intraventricular septal thickness) [31]. In a recent publication, Lin et al. reported that serum creatinine and cystatine $C$ are inversely associated with VD in a cohort of 26 patients with $\mathrm{FD}^{55}$. Our findings show that lysoGb3 seems to be inversely associated with both VD and VLD in the SCP and DCP. To our knowledge, lysoGb3 is the 
only FD-specific systemic biomarker for which associations with OCTA parameters have been observed.

Our results further support the hypothesis posed by Cennamo et al., that OCTA could represent a valid biomarker to predict systemic involvement in FD. Early detection of changes in OCTA parameters might be useful in identifying patients with subclinical systemic findings and, as has been outlined before, enable more effective ERT. This might be a key factor in preventing irreversible organ damage and development of more severe complications. In heterozygous females, $\alpha$-Gal A activity can vary widely due to random X-chromosome inactivation [10] and female FD patients typically suffer from less and milder symptoms than male FD patients [52]. In accord with these findings by Nowak et al., we could only detect associations of lysoGb3 and OCTA parameters for VD and VLD in SCP in the male subgroup, not in the female subgroup. We suspect, this could be due to the milder manifestations in females with a lower mean and lower standard deviation of lysoGb3 in the female subgroup, even though the female subgroup was larger in our study.

The main limitations of this study are its retrospective nature, the limited sample size which is inevitable in rare diseases and the imbalance of lysoGb3 values in the male and female cohort.

\section{Conclusions}

In conclusion, our study shows an association between a FD specific parameter, lysoGb3, and quantitative OCTA parameters. The observed decrease of VD and VLD in patients with higher lysoGb3 supports the hypothesis that quantitative OCTA parameters might be useful as diagnostic biomarkers for evaluating systemic involvement in FD, and possibly other diseases.

Further prospective controlled trials with a large sample size and a long follow up to assess the dynamic changes of OCTA parameters with changing lysoGb3 values are highly demanded.

Author Contributions: Conceptualization, M.R.J.W. and S.A.Z.; methodology, M.R.J.W., T.H. and S.A.Z.; software, M.R.J.W., T.H.; validation, M.D.T., T.H. and S.A.Z.; formal analysis, M.R.J.W.; investigation, K.F., A.N., M.A.-S., J.B., S.A.Z.; resources, S.A.Z.; data curation, M.R.J.W., K.F., J.B.; writing—original draft preparation, M.R.J.W., M.D.T.; writing—review and editing, M.R.J.W., M.D.T., A.N., S.A.Z.; visualization, M.R.J.W., M.D.T.; supervision, S.A.Z.; project administration, A.N., S.A.Z.; funding acquisition: S.A.Z. All authors have read and agreed to the published version of the manuscript.

Funding: Novartis Pharma CH AG (unrestricted research grant).

Institutional Review Board Statement: The study was conducted according to the guidelines of the Declaration of Helsinki, and approved by the Institutional Ethics Commitee of the Canton of Zurich (BASEC-No. 2019-02043).

Informed Consent Statement: Informed consent was obtained from all subjects involved in the study.

Data Availability Statement: Data will be made available upon request to the corresponding author.

Conflicts of Interest: The authors declare no conflict of interest.

\section{References}

1. Sodi, A.; Guarducci, M.; Vauthier, L.; Ioannidis, A.S.; Pitz, S.; Abbruzzese, G.; Sofi, F.; Mecocci, A.; Miele, A.; Menchini, U. Computer assisted evaluation of retinal vessels tortuosity in Fabry disease. Acta Ophthalmol. 2012, 91, e113-e119. [CrossRef]

2. Desnick, R.; Ioannou, Y.; Eng, C. $\alpha$-galactosidase A deficiency: Fabry disease. In The Metabolic and Molecular Bases of Inherited Disease; Scriver, C.R., Beaudet, A.L., Sly, W.S., Valle, D., Eds.; The McGraw-Hill Companies Inc.: New York, NY, USA, 2001; pp. 3733-3774.

3. Kramer, J.; Weidemann, F. Biomarkers for Diagnosing and Staging of Fabry Disease. Curr. Med. Chem. 2018, $25,1530-1537$. [CrossRef]

4. San Roman, I.; Rodriguez, M.E.; Caporossi, O.; Zoppetti, C.; Sodi, A.; Mecocci, A.; López, D.; Rodríguez, B.; Gimeno, J.R. Computer Assisted Retinal Vessel Tortuosity Evaluation in Novel Mutation Fabry Disease: Towards New Prognostic Markers. Retina 2017, 37, 592-603. [CrossRef] [PubMed] 
5. Siegenthaler, M.; Huynh-Do, U.; Krayenbuehl, P.; Pollock, E.; Widmer, U.; Debaix, H.; Olinger, E.; Frank, M.; Namdar, M.; Ruschitzka, F.; et al. Impact of cardio-renal syndrome on adverse outcomes in patients with Fabry disease in a long-term follow-up. Int. J. Cardiol. 2017, 249, 261-267. [CrossRef]

6. $\quad$ Desnick, R.J.; Wasserstein, M.P.; Banikazemi, M. Fabry Disease ( $\alpha$-Galactosidase A Deficiency): Renal Involvement and Enzyme Replacement Therapy. Proteom. Nephrol. 2001, 136, 174-192. [CrossRef]

7. Meikle, P.J.; Hopwood, J.J.; Clague, A.E.; Carey, W.F. Prevalence of Lysosomal Storage Disorders. JAMA 1999, 281, 249-254. [CrossRef] [PubMed]

8. Desnick, R.J.; Brady, R.; Barranger, J.; Collins, A.J.; Germain, D.P.; Goldman, M.; Grabowski, G.; Packman, S.; Wilcox, W.R. Fabry Disease, an Under-Recognized Multisystemic Disorder: Expert Recommendations for Diagnosis, Management, and Enzyme Replacement Therapy. Ann. Intern. Med. 2003, 138, 338-346. [CrossRef]

9. Desnick, R.J.; Ioannou, Y.A.; Eng, C.M. $\alpha$-Galactosidase A Deficiency: Fabry Disease. In The Online Metabolic and Molecular Bases of Inherited Disease; Beaudet, A.L., Vogelstein, B., Kinzler, K.W., Eds.; The McGraw-Hill Companies Inc.: New York, NY, USA, 2014.

10. Echevarria, L.; Benistan, K.; Toussaint, A.; Dubourg, O.; Hagege, A.A.; Eladari, D.; Jabbour, F.; Beldjord, C.; De Mazancourt, P.; Germain, D.P. X-chromosome inactivation in female patients with Fabry disease. Clin. Genet. 2016, 89, 44-54. [CrossRef]

11. Germain, D.P.; Charrow, J.; Desnick, R.J.; Guffon, N.; Kempf, J.; Lachmann, R.H.; Lemay, R.; Linthorst, G.E.; Packman, S.; Scott, C.R.; et al. Ten-year outcome of enzyme replacement therapy with agalsidase beta in patients with Fabry disease. J. Med Genet. 2015, 52, 353-358. [CrossRef]

12. Francois, J.; Hanssens, M.; Teuchy, H. Corneal Ultrastructural Changes in Fabry's Disease. Int. J. Ophthalmol. 1978, 176, 313-330. [CrossRef]

13. Tuppurainen, K.; Collan, Y.; Rantanen, T.; Hollmen, A. Fabry's disease and cornea verticillata. A report of 3 cases. Acta Ophthalmol. 1981, 59, 674-682. [CrossRef]

14. Macrae, W.; Ghosh, M.; McCulloch, C. Corneal changes in Fabry's disease: A clinico-pathologic case report of a heterozygote. Ophthalmic Paediatr. Genet. 1985, 5, 185-190. [CrossRef]

15. Sodi, A.; Ioannidis, A.S.; Mehta, A.; Davey, C.; Beck, M.; Pitz, S. Ocular manifestations of Fabry's disease: Data from the Fabry Outcome Survey. Br. J. Ophthalmol. 2007, 91, 210-214. [CrossRef] [PubMed]

16. Samiy, N. Ocular Features of Fabry Disease: Diagnosis of a Treatable Life-threatening Disorder. Surv. Ophthalmol. 2008, 53, 416-423. [CrossRef]

17. Desnick, R.J. Enzyme replacement therapy for Fabry disease: Lessons from two $\alpha$-galactosidase A orphan products and one FDA approval. Expert Opin. Biol. Ther. 2004, 4, 1167-1176. [CrossRef] [PubMed]

18. Desnick, R.; Schuchman, E. Enzyme Replacement Therapy for Lysosomal Diseases: Lessons from 20 Years of Experience and Remaining Challenges. Annu. Rev. Genom. Hum. Genet. 2012, 13, 307-335. [CrossRef] [PubMed]

19. Schiffmann, R.; Kopp, J.B.; Austin, H.A., III; Sabnis, S.; Moore, D.F.; Weibel, T.; Balow, J.E.; Brady, R.O. Enzyme replacement therapy in Fabry disease: A randomized controlled trial. JAMA 2001, 285, 2743-2749. [CrossRef] [PubMed]

20. Germain, D.P.; Hughes, D.A.; Nicholls, K.; Bichet, D.G.; Giugliani, R.; Wilcox, W.R.; Feliciani, C.; Shankar, S.P.; Ezgu, F.; Amartino, H.; et al. Treatment of Fabry's Disease with the Pharmacologic Chaperone Migalastat. N. Engl. J. Med. 2016, 375, 545-555. [CrossRef]

21. Germain, D.P.; Elliott, P.M.; Falissard, B.; Fomin, V.V.; Hilz, M.J.; Jovanovic, A.; Kantola, I.; Linhart, A.; Mignani, R.; Namdar, M.; et al. The effect of enzyme replacement therapy on clinical outcomes in male patients with Fabry disease: A systematic literature review by a European panel of experts. Mol. Genet. Metab. Rep. 2019, 19, 100454. [CrossRef]

22. Lenders, M.; Brand, E. Effects of Enzyme Replacement Therapy and Antidrug Antibodies in Patients with Fabry Disease. J. Am. Soc. Nephrol. 2018, 29, 2265-2278. [CrossRef]

23. Spaide, R.F.; Fujimoto, J.G.; Waheed, N.K.; Sadda, S.R.; Staurenghi, G. Optical coherence tomography angiography. Prog. Retin. Eye Res. 2018, 64, 1-55. [CrossRef]

24. Spaide, R.F.; Klancnik, J.M.; Cooney, M.J. Retinal Vascular Layers Imaged by Fluorescein Angiography and Optical Coherence Tomography Angiography. JAMA Ophthalmol. 2015, 133, 45-50. [CrossRef] [PubMed]

25. Bonfiglio, V.; Ortisi, E.; Scollo, D.; Reibaldi, M.; Russo, A.; Pizzo, A.; Faro, G.; Macchi, I.; Fallico, M.; Toro, M.D.; et al. Vascular changes after vitrectomy for rhegmatogenous retinal detachment: Optical coherence tomography angiography study. Acta Ophthalmol. 2019, 98, e563-e569. [CrossRef]

26. Wrzesińska, D.; Nowomiejska, K.; Nowakowska, D.; Toro, M.D.; Bonfiglio, V.; Reibaldi, M.; Avitabile, T.; Rejdak, R. Secondary Vitrectomy with Internal Limiting Membrane Plug due to Persistent Full-Thickness Macular Hole OCT-Angiography and Microperimetry Features: Case Series. J. Ophthalmol. 2020, 2020, 1-9. [CrossRef] [PubMed]

27. Carnevali, A.; Mastropasqua, R.; Gatti, V.; Vaccaro, S.; Mancini, A.; D’Aloisio, R.; Lupidi, M.; Cerquaglia, A.; Sacconi, R.; Borrelli, E.; et al. Optical Coherence Tomography Angiography in Intermediate and Late Age-Related Macular Degeneration: Review of Current Technical Aspects and Applications. Appl. Sci. 2020, 10, 8865. [CrossRef]

28. Cennamo, G.; Di Maio, L.G.; Montorio, D.; Tranfa, F.; Russo, C.; Pontillo, G.; Cocozza, S.; Esposito, R.; Di Risi, T.; Imbriaco, M.; et al. Optical Coherence Tomography Angiography Findings in Fabry Disease. J. Clin. Med. 2019, 8, 528. [CrossRef]

29. Minnella, A.M.; Barbano, L.; Verrecchia, E.; Martelli, F.; Pagliei, V.; Gambini, G.; Placidi, G.; Falsini, B.; Caporossi, A.; Manna, R. Macular Impairment in Fabry Disease: A Morpho-functional Assessment by Swept-Source OCT Angiography and Focal Electroretinography. Investig. Opthalmol. Vis. Sci. 2019, 60, 2667-2675. [CrossRef] 
30. Cakmak, A.I.; Atalay, E.; Cankurtaran, V.; Yaşar, E.; Turgut, F.H. Optical coherence tomography angiography analysis of fabry disease. Int. Ophthalmol. 2020, 40, 3023-3032. [CrossRef] [PubMed]

31. Cennamo, G.; Montorio, D.; Santoro, C.; Cocozza, S.; Spinelli, L.; Di Risi, T.; Riccio, E.; Russo, C.; Pontillo, G.; Esposito, R.; et al. The Retinal Vessel Density as a New Vascular Biomarker in Multisystem Involvement in Fabry Disease: An Optical Coherence Tomography Angiography Study. J. Clin. Med. 2020, 9, 4087. [CrossRef]

32. Donati, S.; Maresca, A.M.; Cattaneo, J.; Grossi, A.; Mazzola, M.; Caprani, S.M.; Premoli, L.; Docchio, F.; Rizzoni, D.; Guasti, L.; et al. Optical coherence tomography angiography and arterial hypertension: A role in identifying subclinical microvascular damage? Eur. J. Ophthalmol. 2021, 31, 158-165. [CrossRef]

33. Gold, H.; Mirzaian, M.; Dekker, N.; Ferraz, M.J.; Lugtenburg, J.; Codée, J.D.C.; Van Der Marel, G.A.; Overkleeft, H.S.; Linthorst, G.E.; Groener, J.E.M.; et al. Quantification of Globotriaosylsphingosine in Plasma and Urine of Fabry Patients by Stable Isotope Ultraperformance Liquid Chromatography-Tandem Mass Spectrometry. Clin. Chem. 2013, 59, 547-556. [CrossRef]

34. Nowak, A.; Mechtler, T.; Kasper, D.C.; Desnick, R.J. Correlation of Lyso-Gb3 levels in dried blood spots and sera from patients with classic and Later-Onset Fabry disease. Mol. Genet. Metab. 2017, 121, 320-324. [CrossRef] [PubMed]

35. Early Treatment Diabetic Retinopathy Study Design and Baseline Patient Characteristics; ETDRS report number 7. Ophthalmology 1991, 98, 741-756. [CrossRef]

36. Al-Sheikh, M.; Falavarjani, K.G.; Akil, H.; Sadda, S.R. Impact of image quality on OCT angiography based quantitative measurements. Int. J. Retin. Vitr. 2017, 3, 1-6. [CrossRef]

37. Carnevali, A.; Sacconi, R.; Corbelli, E.; Tomasso, L.; Querques, L.; Zerbini, G.; Scorcia, V.; Bandello, F.; Querques, G. Optical coherence tomography angiography analysis of retinal vascular plexuses and choriocapillaris in patients with type 1 diabetes without diabetic retinopathy. Acta Diabetol. 2017, 54, 695-702. [CrossRef]

38. Cicinelli, M.V.; Rabiolo, A.; Marchese, A.; De Vitis, L.; Carnevali, A.; Querques, L.; Bandello, F.; Querques, G. Choroid morphometric analysis in non-neovascular age-related macular degeneration by means of optical coherence tomography angiography. $\mathrm{Br}$. $\mathrm{J}$. Ophthalmol. 2017, 101, 1193-1200. [CrossRef]

39. Wanner, C.; Feldt-Rasmussen, U.; Jovanovic, A.; Linhart, A.; Yang, M.; Ponce, E.; Brand, E.; Germain, D.P.; Hughes, D.A.; Jefferies, J.L.; et al. Cardiomyopathy and kidney function in agalsidase beta-treated female Fabry patients: A pre-treatment vs. post-treatment analysis. ESC Hear. Fail. 2020, 7, 825-834. [CrossRef] [PubMed]

40. Franzen, D.; Haile, S.R.; Kasper, D.C.; Mechtler, T.P.; Flammer, A.J.; Krayenbühl, P.A.; Nowak, A. Pulmonary involvement in Fabry disease: Effect of plasma globotriaosylsphingosine and time to initiation of enzyme replacement therapy. BMJ Open Respir. Res. 2018, 5, e000277. [CrossRef]

41. Sims, K.; Politei, J.; Banikazemi, M.; Lee, P. Stroke in Fabry disease frequently occurs before diagnosis and in the absence of other clinical events: Natural history data from the Fabry Registry. Stroke 2009, 40, 788-794. [CrossRef] [PubMed]

42. Nowak, A.; Mechtler, T.P.; Hornemann, T.; Gawinecka, J.; Theswet, E.; Hilz, M.J.; Kasper, D.C. Genotype, phenotype and disease severity reflected by serum LysoGb3 levels in patients with Fabry disease. Mol. Genet. Metab. 2018, 123, 148-153. [CrossRef] [PubMed]

43. Aerts, J.M.; Groener, J.E.; Kuiper, S.; Donker-Koopman, W.E.; Strijland, A.; Ottenhoff, R.; Van Roomen, C.; Mirzaian, M.; Wijburg, F.A.; Linthorst, G.E.; et al. Elevated globotriaosylsphingosine is a hallmark of Fabry disease. Proc. Natl. Acad. Sci. USA 2008, 105, 2812-2817. [CrossRef]

44. Jung, S.C.; Park, E.S.; Choi, J.O.; Park, J.W.; Lee, M.H.; Park, H.Y. Expression of genes and their responses to enzyme replacement therapy in a Fabry disease mouse model. Int. J. Mol. Med. 2009, 24, 401-407. [CrossRef] [PubMed]

45. Rozenfeld, P.; Agriello, E.; De Francesco, N.; Martinez, P.; Fossati, C. Leukocyte perturbation associated with Fabry disease. J. Inherit. Metab. Dis. 2009, 32, 67-77. [CrossRef] [PubMed]

46. Biancini, G.B.; Vanzin, C.S.; Rodrigues, D.B.; Deon, M.; Ribas, G.S.; Barschak, A.G.; Manfredini, V.; Netto, C.B.; Jardim, L.B.; Giugliani, R.; et al. Globotriaosylceramide is correlated with oxidative stress and inflammation in Fabry patients treated with enzyme replacement therapy. Biochim. Biophys. Acta Mol. Basis Dis. 2012, 1822, 226-232. [CrossRef]

47. Biancini, G.B.; Moura, D.J.; Manini, P.R.; Faverzani, J.L.; Netto, C.B.O.; Deon, M.; Giugliani, R.; Saffi, J.; Vargas, C.R. DNA damage in Fabry patients: An investigation of oxidative damage and repair. Mutat. Res. Toxicol. Environ. Mutagen. 2015, 784-785, 31-36. [CrossRef]

48. Matafora, V.; Cuccurullo, M.; Beneduci, A.; Petrazzuolo, O.; Simeone, A.; Anastasio, P.; Mignani, R.; Feriozzi, S.; Pisani, A.; Comotti, C.; et al. Early markers of Fabry disease revealed by proteomics. Mol. Biosyst. 2015, 11, 1543-1551. [CrossRef]

49. Ko, Y.; Lee, C.; Moon, M.H.; Hong, G.R.; Cheon, C.K.; Lee, J.S. Unravelling the mechanism of action of enzyme replacement therapy in Fabry disease. J. Hum. Genet. 2015, 61, 143-149. [CrossRef]

50. Weidemann, F.; Sanchez-Niño, M.D.; Politei, J.; Oliveira, J.P.; Wanner, C.; Warnock, D.G.; Ortiz, A. Fibrosis: A key feature of Fabry disease with potential therapeutic implications. Orphanet J. Rare Dis. 2013, 8, 116. [CrossRef]

51. Nowak, A.; Mechtler, T.P.; Desnick, R.J.; Kasper, D.C. Plasma LysoGb3: A useful biomarker for the diagnosis and treatment of Fabry disease heterozygotes. Mol. Genet. Metab. 2017, 120, 57-61. [CrossRef]

52. Nowak, A.; Huynh-Do, U.; Krayenbuehl, P.; Beuschlein, F.; Schiffmann, R.; Barbey, F. Fabry disease genotype, phenotype, and migalastat amenability: Insights from a national cohort. J. Inherit. Metab. Dis. 2020, 43, 326-333. [CrossRef] [PubMed] 
53. Cordon, B.; Vilades, E.; Orduna, E.; Satue, M.; Perez-Velilla, J.; Sebastian, B.; Polo, V.; Larrosa, J.M.; Pablo, L.E.; Garcia-Martin, E. Angiography with optical coherence tomography as a biomarker in multiple sclerosis. PLoS ONE 2020, 15, e0243236. [CrossRef] [PubMed]

54. Pellegrini, M.; Vagge, A.; Desideri, L.F.F.; Bernabei, F.; Triolo, G.; Mastropasqua, R.; Del Del Noce, C.; Borrelli, E.; Sacconi, R.; Iovino, C.; et al. Optical Coherence Tomography Angiography in Neurodegenerative Disorders. J. Clin. Med. 2020, 9, 1706. [CrossRef] [PubMed]

55. Lin, Z.; Pan, X.; Mao, K.; Jiao, Q.; Chen, Y.; Zhong, Y.; Cheng, Y. Quantitative evaluation of retinal and choroidal changes in Fabry disease using optical coherence tomography angiography. Lasers Med. Sci. 2021, 1-9. [CrossRef] 